\title{
A AULA DE FILOSOFIA COMO OFICINA DE CRIAÇÃO
}

\author{
Felipe Araújo ${ }^{1}$ \\ Filipe Ceppas
}

RESUMO: $O$ presente trabalho explora uma concepção de ensino de filosofia como ato de criação, e não apenas de reprodução, o que o aproxima da atividade artística. Apresentamos, em primeiro lugar, a tese de Deleuze e Guattari de que a atividade filosófica consiste no processo de criar conceitos e que estes são ferramentas de intervenção no mundo. A partir daí, defendemos a atividade do professor de filosofia como uma oficina, onde essas ferramentas podem ser utilizadas, ou mesmo novas ferramentas criadas, sempre que necessário, sempre que os problemas assim o exigirem.

PALAVRAS-CHAVE: Conceito; Caixa de Ferramentas; Criação.

RESUMEN: En este trabajo se explora una concepción de la enseñanza de la filosofía como un acto de creación, y no sólo de reproducción, acercándose a la actividad artística. Presentamos las tesis de Deleuze y Guattari que afirman que la actividad filosófica es el proceso de creación de conceptos y estes, por su vez, son herramientas de intervención en el mundo. A partir de ahí, abogamos por la actividad de profesor de filosofía como un taller en el que se pueden utilizar estas herramientas o incluso 
A AULA DE FILOSOFIA COMO OFICINA DE CRIAÇÃO

nuevas herramientas son creadas, siempre que sea necesario, cuando los problemas así lo exigen.

PALAVRAS CLAVE: Concepto; Caja de Herramientas; Creación. 
A função da filosofia não é a de repetir interpretações de mundo já propostas por filósofos ao longo de sua história. Filosofaré, como defendem Deleuze e Guattari, criar conceitos (DELEUZE \& GUATTARI, 1992). A tarefa do filósofo não é reprodução, mas invenção. Fazer filosofia é trabalhar com a criação, seja na proposição de novos conceitos que servirão para responder a problemas e questões que se apresentam no horizonte, seja no pensar de maneira diferenciada problemas e conceitos sobre os quais os filósofos anteriores se debruçaram. Com isso, o exercício filosófico não exclui o estudo da História da Filosofia, mas este estudo também não pode ser entendido como centro do processo filosófico e do ensino-aprendizado da filosofia.

Arte e filosofia guardam em comum essa característica: a necessidade da criação. Não há arte em apenas reproduzir o que já foi criado, ainda que essa repetição possa ser executada a partir de técnicas e habilidades excepcionais. Um pianista que executa obras de Beethoven de maneira idêntica àquela aparentemente idealizada pelo compositor, seguindo do modo o mais fiel possível as indicações da partitura, não é necessariamente um artista criador. Mas é claro que existem artistas intérpretes criativos - e esse talvez seja um diferencial importante, passível de ser explorado a partir da especificidade da arte enquanto puro bloco de sensações, de composição entre afectos e perceptos.

O estudioso de filosofia que quisesse reproduzir exatamente os conceitos criados por um determinado filósofo, ou mostrar-lhes a "forma correta", apresentá-los fielmente, não está, a rigor, segundo a definição de Deleuze, fazendo filosofia. Ainda que o faça de maneira magistral, essa habilidade não o torna filósofo. 
Para falar a verdade, as ciências, as artes, as filosofias são igualmente criadoras, mesmo se compete apenas à filosofia criar conceitos no sentido estrito. Os conceitos não nos esperam inteiramente feitos, como corpos celestes. Não há céu para os conceitos. Eles devem ser inventados, fabricados ou antes criados, e não seriam nada sem a assinatura daquelas que os criam. Nietzsche determinou a tarefa da filosofia quando escreveu: "Os filósofos não devem mais contentar-se em aceitar os conceitos que lhe são dados, para somente limpá-los e fazê-los reluzir, mas é necessário que eles comecem por fabricá-los, criá-los, afirmá-los, persuadindo os homens a utilizá-los. Até o presente momento, tudo somado, cada um tinha confiança em seus conceitos, como num dote miraculoso vindo de algum mundo igualmente miraculoso", mas é necessário substituir a confiança pela desconfiança, e é dos conceitos que o filósofo deve desconfiar mais, desde que ele mesmo não os criou... Que valeria um filósofo do qual se pudesse dizer: ele não criou um conceito, ele não criou seus conceitos? (DELEUZE \& GUATTARI, 1992, p.11-12).

Talvez um "repetidor da história da filosofia" possa se considerar um bom professor de filosofia, mas mesmo essa opção parece problemática, se levamos em conta as ideias de Deleuze. É evidente que, para um professor de filosofia (e sobretudo tal como a transmissão da filosofia é costumeiramente compreendida, como apresentação da história da filosofia), é necessário percorrer um bom número de filósofos anteriores, tal como um músico precisa recorrer aos clássicos da música para se tornar um músico virtuoso. 
Vemos, portanto, que alguns paralelos entre arte e filosofia nos ajudam a pensar a relação entre filosofar e ensinar a filosofia ou a filosofar. Ensinar filosofia e se apropriar de sua história não são garantias para que alguém, seja o professor, seja o aluno, se torne um filósofo, do mesmo modo como o ensino de arte não faz do estudante, ou do professor, um artista.

A concepção deleuziana de filosofia tem sido usada, há muito tempo, como uma crítica ao método acadêmico de se interpretar a atividade filosófica e o ensino de filosofia. Costumeiramente, a tradição acadêmica brasileira estimula a mera reprodução de métodos e conceitos já trabalhados pelos filósofos, e essa prática tem importantes reflexos no ensino de filosofia no nível de Ensino Médio. O resultado é paradoxal. Por um lado, há uma identidade entre fazer, ensinar e aprender filosofia: ensinar e aprender filosofia é ensinar e aprender aquilo que os filósofos já fizeram. E o ensino de filosofia no Ensino Médio disso se diferenciaria apenas porque seria realizado num nível mais primário, introdutório. Por outro lado, se o ensino e o aprendizado da filosofia seria o ensino e o aprendizado daquilo que os filósofos fizeram, forçoso seria aprender a filosofar criando conceitos novos, que é o que os filósofos sempre fizeram.

Mas o divórcio entre a prática acadêmica e o ensino de filosofia no Ensino Médio não é apenas de intensidade. Há uma certa ideia de que o rigor acadêmico confere natureza filosófica ao trabalho do comentário, de reapropriação de determinados problemas, de determinados conceitos. O professor universitário, pesquisador, pode não dizer nada de novo, para além do esclarecimento de um parágrafo, da 
ambiguidade de um conceito alheio, pode não ter nenhuma ideia própria, para além de uma certa fixação em como ler um determinado autor, em como pensar um determinado problema, mas o que ele faz seria filosofia porque seria "rigoroso"; enquanto a repetição por assim dizer "mais livre", mais tateante, ou mesmo mais "selvagem" da história da filosofia, num curso de Ensino Médio por exemplo, seria menor, menos filosófica. Reinstaura-se, assim, o divórcio entre fazer filosofia e ensinar filosofia, enquanto uma disciplina que somente reproduz, repete, e não necessariamente se reapropria das contribuições da história da filosofia.

A aproximação da filosofia com a arte nos força a questionar essa concepção acadêmica do ensino de filosofia e a reconhecer uma outra questão, que é a da relação entre o filosófico e o não-filosófico. Essa questão é essencial para o ensino de filosofia no Ensino Médio, uma vez que, nele, diferentemente da academia, o trabalho é feito com pessoas que não têm necessariamente interesse pela filosofia e nem precisam ter. Na perspectiva deleuziana, essa aproximação com a arte não é meramente acessória, mas constitutiva:

A relação entre o filosófico e o não-filosófico está no coração do conceito de filosofia deleuziano. Não se entende a filosofia, se dela também não se tem uma compreensão não-conceitual, não-filosófica. A compreensão não-filosófica se dá por perceptos e afetos, que são blocos de sensação, objetos próprios da criação artística. Só entendemos o que é a filosofia quando temos as duas compreensões, a conceitual e a 
não-conceitual, as duas audições, a filosófica e a nãofilosófica. Isso se dá quando relacionarmos o conceito e a sensação. (VIEGAS, 2011, p.8).

Disso decorre um segundo paralelo entre filosofia e arte: ambas as atividades se aproximam, ao relacionar conceito e "sensação" (ou toda uma estrutura da percepção que necessariamente acompanha o pensar) como elementos que não podem ser separados, sob o risco de tornar o conceito algo vazio; e a sensação, "cega". A partir dessa concepção, podemos defender o uso das linguagens artísticas como elemento fundamental de sensibilização para as questões filosóficas. Como defende Deleuze, a filosofia deve se dirigir a filósofos e não-filósofos, assim como a pintura se dirige a pintores e não pintores.

Uma "boa aula" é como um concerto. A emoção é tão fundamental quanto a inteligência. Cada estudante irá pegar o que lhe interessa, o que lhe sensibiliza as emoções de forma significativa. É possível que uma aula não convenha a ninguém, nesse caso, aconteceria uma aula ruim. Para que os estudantes sejam tocados, sensibilizados, é necessário que o professor também fale sobre algo que ache interessante, é preciso entusiasmo, e isso pressupõe o ensaio. Tal como numa peça de teatro, é a preparação, o ensaio, que permitirá momentos de inspiração. Nesse sentido, uma aula de filosofia exige muita preparação, muito ensaio. Ao juntar esses elementos, ensaio, preparo, inspiração e emoção, tem-se o ambiente propício para que ocorra o que Deleuze caracteriza como um canto falado. 
O canto falado é a expressão do grito, requisito para a atividade filosófica. Filosofar é também gritar. Gritar é mais uma necessidade do que um prazer. Gritamos porque precisamos resolver algo que nos incomoda, porque precisamos resolver esse problema que nos afeta. Não há criação quando há ausência de sentido. Nesses momentos, a repetição (recognição) é que atua. A criação atua quando há um problema, quando um "grito" irrompe de maneira inesperada e repercute no pensamento como problema a ser resolvido, e para o qual nenhum saber ou conhecimento tem uma resposta; por isso o pensamento é impelido a criar, a inventar uma solução. Os conceitos têm essa finalidade: organizar os gritos que estão engasgados em nós. "Os conceitos são a forma do grito" e, ao trabalhar esse grito, o transformamos em canto. É como canto que os gritos se resolvem, que os problemas são resolvidos (ainda que provisoriamente).

Tal como num concerto, uma aula de filosofia é um canto falado. Nossos problemas e conceitos interagem. Se os ouvintes estão disponíveis, se há abertura para o despertar do interesse, fica possível a atuação da emoção e os problemas que emergem do professor dialogam com as questões e problemas presentes naqueles que o ouvem. E, para que os ouvintes estejam disponíveis, é preciso que o professor perceba a necessidade de se criar um ambiente propício. Nada disso é evidente, mas já ajuda saber quais elementos podem compor uma aula entendida como "canto falado", quais seriam suas exigências.

Ouvir as aulas como se ouve um concerto musical, ou seja, com abertura, com atenção - nada parece mais distante 
das condições de uma aula no Ensino Médio. Podemos arriscar que as questões que emergem possam ser digeridas se puderem vir a se tornar gritos, a serem posteriormente "resolvidos". Essa "resolução" não implicaria necessariamente duelos de argumentações, "discussão". Contra a ideia de um duelo que estabeleceria a verdade, pensamos num convite a conversações. O ensaio do professor e a abertura do aluno permitem que as conversações aconteçam e que problemas comuns, ou próximos, ou convergentes, sejam trabalhados. E todo problema exige uma "solução", que não seria nada além de uma experiência filosófica do pensamento, e não o estabelecimento de uma "verdade".

Nesse sentido é que pensamos a filosofia como uma "Caixa de Ferramenta", como nos sugere Deleuze. Não se trata de mera análise da realidade, mas de instrumento, de ferramenta para a modificação da realidade.

Uma teoria é como uma caixa de ferramentas. Nada tem a ver com o significante... É preciso que sirva, é preciso que funcione. E não para si mesma. Se não há pessoas para utilizá-la, a começar pelo próprio teórico que deixa então de ser teórico, é que ela não vale nada ou que o momento ainda não chegou. Não se refaz uma teoria, fazem-se outras; há outras a serem feitas. É curioso que seja um autor que é considerado um puro intelectual, Proust, que o tenha dito tão claramente: tratem meus livros como óculos dirigidos para fora e se eles não lhes servem, consigam outros, encontrem vocês mesmos seu instrumento, que é forçosamente um instrumento de combate. (Deleuze apud FOUCAULT, 1989, p. 71). 
Para continuar nesta analogia, seria oportuno que a sala de aula se transformasse em uma oficina, em um atelier de criação, onde se aprende a usar as várias ferramentas de que dispomos. Cada ferramenta serve para resolver um problema específico. Se precisamos pregar, usamos o martelo; se precisamos cortar algo, usamos o serrote; mas se precisamos colorir, usamos o pincel. Se sentimos necessidade de uma cadeira, e decidimos construir uma, não poderemos fazê-lo apenas com um martelo, ou com o serrote. Usamos ferramentas conforme percebemos os problemas a serem resolvidos. Com a filosofia não é diferente. Temos um problema e queremos resolvê-lo. Antes de nós, vários filósofos desenvolveram ferramentas (conceitos) muito eficientes, o que nos permite construir as mais diversas variedades de artefatos; porém, as necessidades não são sempre as mesmas. Sempre se nos apresentam novos problemas, o que nos exige construir novas e específicas ferramentas, para resolver problemas também novos e específicos.

A aula de filosofia pode ser vista como uma oficina de criação, a "antessala da atividade filosófica", e o professor é aquele que vai apresentar as ferramentas para os alunos, explicar como cada uma delas pode ser usada, como funcionam melhor. Nesse sentido, o mestre nada tem de diferente do discípulo, a não ser o fato de utilizar as ferramentas há mais tempo do que a maioria deles. $\mathrm{O}$ professor é um artífice, tal como os alunos, um artífice que aprende no exercício de sua atividade e, nesse exercício, faz os outros aprenderem também. 
Cada um irá descobrir sua maneira de fazer, uns mais interessados em escultura, outros na marcenaria, outros na carpintaria. Cada aluno, ainda, imprimirá seu estilo na obra, cada um deixará sua assinatura, que expressa seu modo de ver, de fazer, de construir o artefato e, portanto, seu modo de se relacionar com o mundo.

Primeiro, todo conceito é necessariamente assinado; cada filósofo, ao criar um conceito, ressignifica um termo da língua com um sentido propriamente seu. (...) A assinatura remete ao estilo filosófico de cada um, à forma particular de pensar e de escrever. "O batismo do conceito solicita um gosto propriamente filosófico que procede com violência ou com insinuação, e que constitui na língua uma língua da filosofia, não somente um vocabulário, mas uma sintaxe que atinge o sublime ou uma grande beleza". A partir disso, Alliez criou a bela imagem da filosofia como uma "assinatura do mundo": cada filósofo assina o mundo à sua maneira, por meio dos conceitos que cria. (GALLO, 2003, p.25).

O professor é aquele que não apenas apresenta os conceitos. É também alguém que, além de explicitar a atividade criativa da filosofia, encoraja e estimula os estudantes a reelaborem criativamente estes conceitos apresentados e, se possível, a criarem seus próprios conceitos. Os conceitos e problemas caminham sempre juntos: o problema exige um conceito, grita por uma solução. O processo seguinte é justamente organizar esse conjunto de ferramentas, de modo que o problema seja solucionado, não necessariamente no sentido de "ser resolvido", mas 
no sentido de se encontrar o melhor meio possível (ainda que provisoriamente) para se lidar com ele. Há aqui, como veremos melhor adiante, uma relação essencial entre o não-filosófico, o pré-filosófico e o filosófico.

Só saber usar as ferramentas não garante nada. É necessário ter claro o que se deseja construir, qual problema se deseja responder, de que forma desejamos intervir no mundo.

(...) a criação de conceitos é uma forma de transformar o mundo; os conceitos são as ferramentas que permitem ao filósofo criar um mundo à sua maneira. Por outro lado, os conceitos podem ainda ser armas para a ação de outros, filósofos ou não, que dispõem deles para fazer a crítica do mundo, para instaurar outros mundos. (...) Que não se faça uma leitura idealista do conceito: não se trata de afirmar que é uma idéia (conceito) que funda a realidade; num sentido completamente outro, o conceito é imanente à realidade, brota dela e serve justamente para fazê-la compreensível. É por isso que o conceito pode ser ferramenta tanto de conservação como de transformação. O conceito é sempre uma intervenção no mundo, seja para conservá-lo, seja para mudá-lo. (GALLO, 2003, 22).

Os conceitos são, portanto, ferramentas analíticas porque nos permitem uma releitura do mundo, mas não somente isso, são também ferramentas de intervenção no mundo. Não devemos filosofar apenas com uma lente de aumento, mas também filosofar com um martelo. Em outras palavras, a filosofia não se esgota em uma interpretação da realidade, mas é também uma modificação da mesma, como defende Marx na $11^{\text {a }}$ tese sobre Feuerbach (MARX \& ENGELS, 1975, p. 24), o que sugere 
que toda análise da realidade é uma tomada de decisão para interferir na própria realidade. "Se é verdade que na história tivemos filosofias e filósofos que agiram no sentido de manter o status quo, também é verdade que tivemos filosofias e filósofos revolucionários, agentes de transformação" (GALLO, 2003, p. 22).

Interferir na realidade não é necessariamente mudá-la, pode-se também querer mantê-la tal como está, o que explica que muitos daqueles que exercitam a intervenção filosófica não necessariamente estão preocupados em revolucionar coisa alguma, mas apenas utilizam as ferramentas conceituais da filosofia para perpetuar o status quo, e talvez sejam maioria. "A filosofia" tem fama de "subversiva", mas talvez não seja um palpite por demais infeliz afirmar que, ao longo da história da humanidade (se é que uma "história da humanidade" já não seja uma sua invenção perversa), ela tem sido muito mais justificadora de verdades que interessam aos poderosos do que fonte de subversão de uma ordem social opressora. Em todo caso, a filosofia envolve sempre a atuação ético-politica, no mínimo por colocar em perspectiva, por tematizar, ainda que dissimuladamente, os dramas e problemas mais significativos da sociedade.

Com isso, chegamos a um ponto importante de nossa conversa, que é o uso das ferramentas para a nossa própria formação. As ferramentas têm como finalidade a construção de nós mesmos, como nos sugere Sônia Campaner, em Filosofia: ensinar e aprender (2012). Primeiramente, porque a tarefa de ouvir nossas próprias palavras e ouvir as palavras dos outros (enquanto possível arranjo ou rearranjo de nossos pensamentos) é essencial, na medida em que possibilita uma síntese, ainda que sempre provisória, de qualquer processo de apreensão ou formulação de conteúdos. Ela é 
uma oportunidade privilegiada para que nós, na medida em que, ao nos reconhecermos como semelhantes, como humanos e animais, como animais humanos, reconhecemonos como formadores de nossa própria cultura e capazes de compreender o sentido de falar e ouvir as palavras dos outros. A radicalidade do questionar se dirige às fontes que alimentam as formas pelas quais nos comportamos, vivemos e conhecemos. Esse exercício de gritar, de recorrer à caixa de ferramentas para sanar a angústia do problema que nos persegue, gera riscos: descobrir as falas e falhas de nossos próprios pensamentos, descobrir as mentiras sociais e pensar o que fazer com essas descobertas.

A escolha da filosofia que seguimos é inseparável da prática didática que realizamos e, portanto, dos conteúdos com os quais decidimos trabalhar. Podemos, por vezes, tomar esta decisão de forma não muito consciente, não tão elaborada, mas concordamos com Sônia Campaner (2012) quando ela diz: "Ao escolher o modo como vamos ensinar (as estratégias didáticas), assumimos uma concepção de filosofia. Não é possível, portanto, fazer escolhas de conteúdo e de didática separadamente". Da mesma forma, acreditamos não ser possível fazer escolhas filosóficas e didáticas separadas das escolhas políticas. Ou seja, defendemos que a docência não se resume a pensar uma prática inovadora dentro da sala de aula, pois a sala de aula é um reflexo da sociedade, repleta de problemas estruturais. É necessário, por isso, avaliar nossa intervenção pedagógica a partir da problemática da educação no mundo moderno. Em um mundo utilitarista, tecnicista, consumista, enfim, capitalista, torna-se fundamental pensar a didática unida à Ética, à Política, à Estética, à Filosofia de uma forma geral. Mas o mesmo se poderia dizer em um mundo que não fosse utilitarista, tecnicista, consumista, 
enfim, capitalista; porque a vida é sempre abertura para a diferença e os conflitos que daí advém.

Neste mundo capitalista, onde predomina um certo utilitarismo selvagem, a "facilidade" ou "dificuldade" da tarefa de sensibilizar os alunos para os problemas filosóficos é uma questão controversa. Esta sensibilização, o cativar os alunos, é muitas vezes concebida como a etapa mais difícil de todo o percurso, visto ser o primeiro desafio que encontramos enquanto educadores. A dificuldade parece se potencializar uma vez que a disciplina filosofia não ocupa um lugar de destaque na grade de disciplinas da Educação Básica, sobretudo nas escolas públicas estaduais, onde os obstáculos são muitos e diversos. Um aspecto fundamental do enfrentamento dessa questão encontra-se na concepção de filosofia que professamos. Se a entendemos como atividade essencialmente contemplativa, o obstáculo parece intransponível, e não apenas porque o mundo nos bombardeia com exigências utilitaristas e a filosofia não seria capaz de responder a essa demanda, mas também porque a maioria dos estudantes, no Ensino Médio, encontra-se numa etapa da vida que clama por prolongar, intensificar e consolidar os sentidos e as relações que eles e elas estabelecem entre os saberes e a experiência.

Neste sentido, não se trata de "baixar" o nível de rigor e profundidade dos problemas da filosofia, de transformála em manual de autoajuda, ou, ainda, justificar sua importância a partir do crescente número de questões de história da filosofia nos vestibulares. Cabe a nós subverter todas essas demandas e mostrar que a filosofia tem um papel fundamental na forma como enxergamos o mundo, na forma como nos enxergamos no mundo, na forma como enxergamos um possível mundo por vir. Justificar a filosofia com a própria filosofia funciona apenas para uma parcela 
muito pequena de pessoas que, por algum motivo, decidiu dedicar-se a ela. Mas, para a imensa maioria, a questão "o que isso vai ajudar na minha vida" é uma questão honesta e filosófica, pois é como uma centelha, a semente de um "grito". Grito que expressa uma espécie de tensionamento, um choque de interesses entre estudantes e professores.

Da mesma maneira que o professor, o estudante também entra na sala de aula com uma bagagem adquirida no decorrer de sua vida, incluindo convicções filosóficas, pedagógicas, políticas. Essas compreensões do mundo, da vida, algumas mais, outras menos conscientes, tanto as dos professores como as dos estudantes, encontram-se via de regra como que em estado de latência. Elas como que pedem para ser testadas, desafiadas, repensadas; elas como que exigem esse momento-espaço próprio da filosofia, possível quase que unicamente na escola, na sala de aula, num contexto ainda não totalmente tomado pelas demandas do dia a dia.

É claro que as convicções dos estudantes volta e meia se chocam com as dos professores, e o simples choque pode mais dificultar do que propiciar um processo de ensinoaprendizado. E não é fácil fazer das diferenças um arranjo que possibilite a convergência dos interesses. Um aluno pode discordar da filosofia do professor, mas se identificar com sua pedagogia, ou, ainda, discordar de seu método pedagógico, mas se interessar pelo problema filosófico. Deleuze dá um exemplo de um aluno que está meio adormecido durante a aula e que acorda misteriosamente, justamente quando o professor trata de uma questão que pareceu interessar a esse aluno, isto é, quando o professor tratou de um problema que lhe diz respeito. Em certa medida, é fundamental que professor e aluno tratem do "mesmo problema". Quando professor e alunos tratam de problemas diferentes, não há 
conversa, quando muito haverá um duelo de convicções, ou o aluno permanecerá o restante da aula adormecido.

Por isso entendemos que a atividade docente da filosofia consiste em se esforçar para que haja, o máximo possível, convergência de problemas; que os problemas dos quais trata o professor dialoguem com os problemas que incomodam os estudantes. Para que esse processo aconteça com mais frequência e precisão é necessário que o professor esteja atento à realidade dos estudantes, é necessária uma abertura para as vivências dos estudantes, para escutar os estudantes. E, também aqui, frente a essa exigência, é importante reforçar o caráter de oficina de uma aula, a partir da noção de criação, irmanando filosofia e linguagens artísticas no que diz respeito ao processo de sensibilização para problemas adormecidos. Nossa concepção do trabalho do professor de filosofia pode ser aproximada, neste sentido, à concepção de teatro de Augusto Boal (1931-2009), que desenvolveu o Teatro do Oprimido com um método que reúne jogos, exercícios e técnicas inspiradas na Pedagogia do Oprimido, de Paulo Freire. Boal defendia que o teatro deveria ser usado como uma espécie de "arte marcial", no sentido de ser um conjunto de técnicas desenvolvidas para enfrentar os vários tipos de opressões (problemas) presentes em nossa sociedade. Em seu livro Teatro do Oprimido e Outras Poéticas Políticas, o autor afirma que "o teatro deve ser um ensaio para a ação na vida real, e não um fim em si mesmo" (2005, p.19). Para o autor, o teatro não deve se limitar a imitar a vida, ou mesmo apenas propor alternativas para vivê-la, mas ele deve ser um treino para a vida que desejamos viver. É nessa linha que concebemos o ensino de filosofia, como um ensaio, uma oficina para enfrentar os problemas comuns a todos e a todas. 


\section{NOTAS}

${ }^{1}$ Professor de Ensino Médio, Seeduc-RJ. Mestrando em Filosofia, UFRJ. E-mail: filos_hipos@hotmail.com.

${ }^{2}$ Doutor em Educação pela Pontifícia Universidade Católica (PUC-Rio). É professor adjunto da Faculdade de Educação da UFRJ e professor do PPGFUFRJ. E-mail: filcepps@gmail.com.

\section{REFERÊNCIAS}

BOAL, Augusto. Teatro do Oprimido e Outras poéticas políticas. Rio de Janeiro: Civilização Brasileira, 2005.

CAMPANER, Sônia. Filosofia: Ensinar e Aprender. São Paulo. Livraria Saraiva. 2012.

DELEUZE, Gilles \& GUATTARI, Félix. O que é a filosofia. Rio de Janeiro: Editora 34, 1992.

FOUCAULT, Michel. Microfísica do Poder. Rio de Janeiro: Graal, 1989.

GALLO, Silvio. Deleuze \& a Educação. Belo Horizonte: Autêntica, 2003.

MARX, Karl e ENGELS, Friedrich. Ludwig Feuerbach e o fim da filosofia clássica alemã. São Paulo: Ed. Estampa, 1975.

VIEGAS, Rogier. O ensino de filosofia como um "canto falado": elementos conceituais da prática docente de Gilles Deleuze. Jornadas sobre la Enseñanza de la Filosofía, 18, 2011, Buneos, 2011. 